\title{
Manipulations of intensity of electric shock in a multiple punishment schedule'
}

DIANE D. EDWARDS AND GAIL DART ${ }^{2}$

UNIVERSITY OF MISSOURI AT KANSAS CITY

\begin{abstract}
Intra-organism comparisons of two shock contingencies replicated effects reported by DeArmond (1966). Increasing the intensity of shock following the first response of each ratio in FR 50 food maintained behavior had little effect on the degree of behavioral suppression produced by less intense shock following each response in a multiple punishment schedule.
\end{abstract}

When electric shock is programmed to occur following every response in the presence of one stimulus condition and to follow only the first response of each ratio in the presence of a second stimulus, differential effects occur (DeArmond, 1966). The specific behavioral effects include complete suppression during FR 1 electric shock and little suppression during first response electric shock. Increasing the duration of each ply of the multiple schedule has little effect on the degree of suppression (Edwards \& Dart, 1966). The present study assessed the effect of increasing shock intensity in the FR 50 shock schedule on suppression in the FR 1 shock schedule.

Subjects

Three white Carneaux pigeons with a history of different punishment schedules and FR 50 reinforcement schedules were maintained at $80 \%$ of their ad lib weights throughout the experiment.

Apparatus

A Lehigh Valley 1519C pigeon box served as the experimental chamber. Punishment was a 60 cycle ac shock delivered through 10,000 ohms in series with the bird. Using a procedure developed by Azrin (1959a), the shock was delivered through electrodes implanted around the pubis bone of the pigeon. Intensity of the shock was regulated by a Variac and measured via a voltmeter. All electrical manipulations were designed by Lehigh Valley, Grason-Stadler, and Scientific Prototype Electronic Companies.

Procedure

A multi-element baseline of responding was established on a FR 50 (at the end of every 50 key pecks, grain was delivered). Red and green lights were alternated on the response key every $15 \mathrm{~min}$, and each experimental session was $30 \mathrm{~min}$ in length.

When stable responding occurred (Schoenfeld, Cummings, \& Hearst, 1956), a punishment contingency was added to each ply of the multiple schedule. For one bird (P69) the red key light set the occasion for FR 50 reinforcement and shock following the first response of each ratio, while the green key light set the occasion for FR 50 reinforcement and shock following every response. The reinforcement contingencies were the same for P91, but the shock contingencies were every response (red) and shock following the first response of each ratio (green). The shock intensity remained equal in both conditions until the behavior in the shock following each response condition was completely suppressed. Following this effect, the intensity of shock was increased by $10 \mathrm{~V}$ every 10 days in the first response shock contingency up to $100 \mathrm{~V}$.

Results

Figure 1 presents representative cumulative records from each manipulation for P91. The first record shows high rate responding in both plys of the multiple schedule. In the second record, complete suppression of responding can be seen at $50 \mathrm{~V}$ of FR 1 shock with only slight deceleration in rates for first response shock. Some post reinforcement pausing can be observed during the final $15 \mathrm{~min}$ of first response shock. When the intensity in first response shock was increased to $70 \mathrm{~V}$ (third record), several responses occur terminating in a burst near the end of the $15 \mathrm{~min}$ of FR $1(50 \mathrm{~V})$ shock. The $70 \mathrm{~V}$ produced no deceleration in rate compared to $50 \mathrm{~V}$ in the second record. At $80 \mathrm{~V}, 17$ ratios were completed in the FR 1 (50 V) shock contingency with little effect in the first response shock contingency $(80 \mathrm{~V})$. When the intensity was increased to $90 \mathrm{~V}$, behavior decelerated to zero in the FR $1(50 \mathrm{~V})$ and only three ratios were completed in the first response shock (90 V) contingency.

Figure 2 presents representative cumulative records for all intensity manipulations for P 69. During baseline (no shock), high rate responding occurred in both

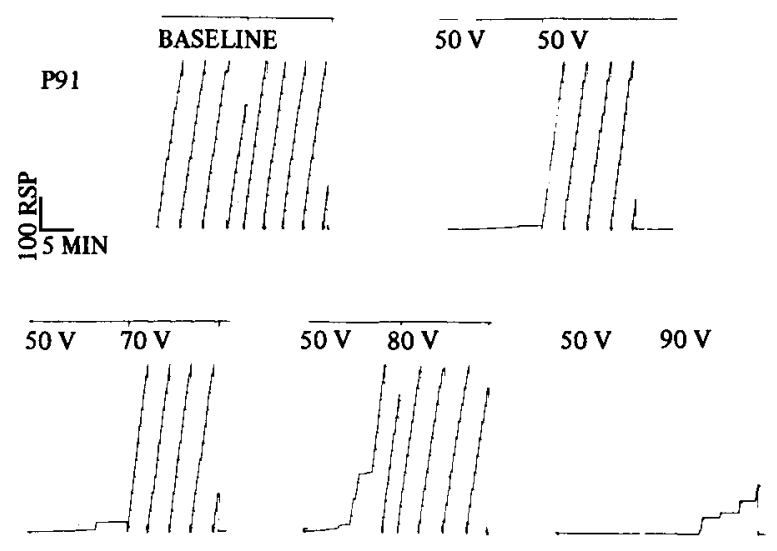

Fig. 1. Representative cumulative records of behavioral effects across differential intensity manipulations for P 91. 


\section{i洒}
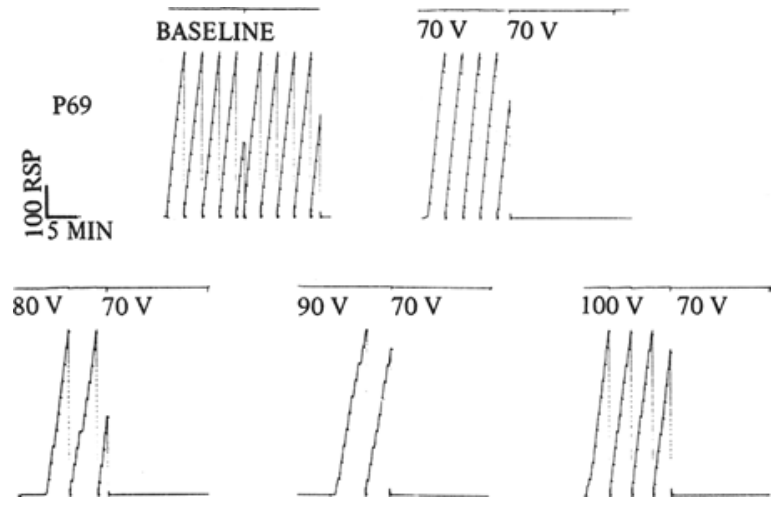

Fig. 1. Representative cumulative records of behavioral effects across differential intensity manipulations for P 69.

red and green key light conditions. When shock intensity was increased to $70 \mathrm{~V}$, rates in first response shock were comparable to baseline, while complete suppression occurred in the FR 1 shock contingency. At $80 \mathrm{~V}$ in first response shock, rates decelerated from baseline rates and complete suppression was observed in FR $1(70 \mathrm{~V})$ shock. Further suppression occurred at $90 \mathrm{~V}$ in first response shock, with no rate in FR 1. At $100 \mathrm{~V}$, some acceleration above that observed at $90 \mathrm{~V}$ occurred in first response shock, but rates remained at zero in $\mathrm{FR} 1(70 \mathrm{~V})$.

\section{Discussion}

Azrin (1959b) introduced a response contingent electric shock following each response on a fixed ratio baseline of behavior. His results showed that punishment had a selective effect on fixed ratio maintained behavior. The local rate was still emitted at high rates, but the postreinforcement pause increased. There was a systematic increase in postreinforcement pause as the intensity of shock increased. Even at $120 \mathrm{~V}$ of electric shock, the local rate was equivalent to prepunishment rates-only the pause following reinforcement increased.

In comparing these effects to those of intermittent schedules of punishment, Dardano \& Sauerbrunn (1964) and De Armond-Edwards (1966) reported that when punishment follows only the first response following reinforcement increased postreinforcement pause is observed. Again this effect is seen at high intensities $(80-120 \mathrm{~V})$.

In the present study when intraorganism comparisons were made of these two punishment schedules, marked differences were observed. Typically complete behavioral suppression occurred when FR 1 shock was only contingent in one ply of a multiple schedule, and very little change occurred in the first response punishment of each ratio. It might be expected that as the intensity of punishment was increased in the intermittent punishment ply that a point would be reached where behavior would return in the continuous punishment ply. However, the results indicate that intermittent punishment has less control over the behavioral effects when programmed in a multiple schedule. In fact, behavior alternated between either complete suppression or complete recovery. Behavior under FR 1 shock never recovered even though these same intensities in other studies (Azrin, 1959b; Dardano \& Sauerbrunn, 1964) had little effect on suppression.

It was not possible to make continuous punishment less effective by increasing the intensity of punishment in the first response punishment ply. In fact, increasing the first response punishment produced behavioral effects equivalent to continuous punishment at intensity differences of about $40 \mathrm{~V}$.

\section{References}

AZRIN, N. H. A technique for delivering shock to pigeons. J. exp. AnaL Behav., 1959a, 2, 161-163.

AZRIN, N. H. Punishment and recovery during fixed-ratio performance. J. exp. A nal Behav., 1959b, 2, 301-305.

DARDANO, J. F., \& SAUERBRUNN, D. Selective punishment of fixedratio behavior. J. exp. Anal. Behav., 1964, 7, 255-260.

DeARMOND, D. Multiple punishment schedule. J. exp. Anal. Behav., 1966, 9, 327-334.

DeARMOND-EDWARDS, D. Concurrent schedules of reinforcement and punishment. Psychon, Sci, 1966, 6, 219-220.

EDWARDS, DIANE D., \& DART, GAIL A. Ply durations in a multiple punishment schedule. Psychon Sci, 1966, 6, 353-354.

SCHOENFELD, W. N., CUMMINGS, W. W., \& HEARST, E. On the classification of reinforcement schedules. Proc. Nat. Acad. Sci, 1956, $42,563-570$.

Notes

1. Research was supported by Grant MH-11205-01 from the National Institute of Mental Health, U.S. Public Health Service to the first author. 2. Now at the University of Maryland. 